Taksonomia 31

ISSN 1899-3192

Klasyfikacja i analiza danych - teoria i zastosowania

\title{
Gregory Kersten
}

InterNeg Research Centre, Concordia University, Montreal

e-mail: gregory@jmsb.concordia.ca

\section{Ewa Roszkowska}

Uniwersytet w Białymstoku

e-mail: erosz@o2.pl

\section{Tomasz Wachowicz}

Uniwersytet Ekonomiczny w Katowicach

e-mail: tomasz.wachowicz@ue.katowice.pl

\section{WPLYW BLĘDÓW PRZETWARZANIA INFORMACJI W SYSTEMACH WSPOMAGANIA NEGOCJACJI NA POROZUMIENIE KOŃCOWE ${ }^{1}$}

\section{THE IMPACT OF INFORMATION PROCESSING ERRORS MADE IN NEGOTIATION SUPPORT SYSTEMS ON THE NEGOTIATION AGREEMENT}

DOI: $10.15611 /$ pn.2018.508.08

JEL Classification: C9, B4, B2

\begin{abstract}
Streszczenie: W pracy zaprezentowano wyniki badań dotyczących wpływu błędów postrzegania i przetwarzania informacji oraz myślenia heurystycznego, obecnych na etapie budowy systemu oceny ofert negocjacyjnych, na porozumienie końcowe w dwustronnych negocjacjach elektronicznych. Do analizy wykorzystano dane negocjacji elektronicznych prowadzonych w Inspire. Wyniki badań wskazują na potrzebę uwzględnienia heurystyk w procesie prenegocjacyjnego przygotowania analitycznego negocjatorów oraz opracowania narzędzi wsparcia negocjatora odpornych na te heurystyki lub redukujących negatywne ich skutki.
\end{abstract}

Słowa kluczowe: wspomaganie negocjacji, informacja preferencyjna, błędy, heurystyki, porozumienie końcowe

Summary: The paper presents the results of experiments on the perception of information and information pro-cessing during the pre-negotiation phase of bilateral online negotiations when they were asked to con-struct a scoring system that represents their preferences. The analysis is based on the dataset of negotia-tions conducted in the online negotiation system Inspire. The results confirm that the negotiators used heuristics during analytical preparation tasks. The paper also discusses the impact of heuristics and information processing on the

\footnotetext{
${ }^{1}$ Praca została sfinansowana ze środków Narodowego Centrum Nauki (2016/21/B/HS4/01583).
} 
substantive outcomes of bilateral online negotiations. The errors made by the participants suggest that tools to support negotiators in their pre-negotiation tasks should be devel-oped so that the negotiators are immune to the heuristics or that their negative effects on are reduced.

Keywords: negotiation support, preferencial information, errors, heuristisc, final agreement.

\section{Wstęp}

Negocjowanie elektroniczne prowadzone za pomocą systemów wspomagania negocjacji czy systemów negocjacji elektronicznych oparte jest na formalnych mechanizmach wspomagania działań analitycznych na etapie przygotowawczym w zakresie definiowania preferencji oraz budowy systemu oceny ofert negocjacyjnych [Raiffa 1982; Kersten, Noronha 1999; Wachowicz 2006, Roszkowska, Wachowicz (red.) 2016]. Mechanizmy te powinny stymulować analityczne i racjonalne działanie negocjatora, realizowane z wykorzystaniem systemu myślenia wolnego [Stanovich, West 2000], którego konsekwencją powinno być wyeliminowanie lub ograniczenie działania heurystyk, dokładniejsze rozpoznanie problemu negocjacyjnego oraz precyzyjna definicja systemu wartościowania poszczególnych rozwiązań negocjacyjnych, będące podstawą podejmowania racjonalnych decyzji podczas negocjacji właściwych. Dzięki systemom oceny można wspomagać negocjatorów w porównywaniu ofert negocjacyjnych, analizie ustępstw, tworzeniu propozycji kontraktu oraz sugerowaniu rozwiązań kompromisowych. Od rzetelnego zdefiniowania takiego systemu przez negocjatora zależy skuteczność udzielonego mu później wsparcia.

Tymczasem wyniki badań eksperymentalnych wskazują między innymi na liczne błędy związane z postrzeganiem procesu tworzenia systemu oceny ofert negocjacyjnych, w tym niewłaściwe operowanie punktami oceny $\mathrm{w}$ metodach ratingu bezpośredniego (np. w metodzie SMARTS [Edwards, Barron 1994]), błędne interpretacje ocen tego systemu, niewłaściwą analizę informacji preferencyjnej [Roszkowska, Wachowicz 2014; 2015; Kersten i in. 2016; 2017]. Wydaje się więc, że negocjatorzy wykorzystujący systemy wspomagania negocjacji oparte na podejściu analitycznym oraz metodach analizy wielokryterialnej stosują heurystyki (reguły wnioskowania pozwalające szybko formułować sądy, przy czym sądy te charakteryzują się dużym stopniem subiektywności), które mogą prowadzić do braku spójności preferencji oraz błędów przy podejmowaniu decyzji [Gilovich i in. 2002; Bazerman, Chung 2005].

Głównym problemem badawczym jest rozpoznanie i ocena wpływu heurystyk na działania negocjatorów podejmowane $\mathrm{w}$ fazie przygotowania do negocjacji. Heurystyki te wpływają na błędy postrzegania i przetwarzania informacji związane z rozpoznaniem i analizą problemu negocjacyjnego oraz budową narzędzi wspomagających dalsze fazy procesu negocjacji elektronicznych, przede wszystkim na konstrukcję systemu oceny ofert negocjacyjnych i weryfikację rzetelności wartościowania pakietów negocjacyjnych realizowanych za jego pomocą. Dokładne 
sprecyzowanie heurystyk i skojarzonych z nimi błędów umożliwi budowę narzędzi wspomagających fazy negocjacji z uwzględnieniem ograniczeń poznawczych negocjatorów.

Celem badań przedstawionych w tym opracowaniu było wyodrębnienie klas błędów popełnianych w ocenie szablonu negocjacyjnego oraz zbadanie wpływu tych błędów na porozumienie końcowe. Przedmiotową analizę przeprowadzono na podstawie danych międzynarodowego eksperymentu negocjacyjnego zrealizowanego w systemie Inspire [Kersten, Noronha 1999].

Analiza danych eksperymentu wskazuje na błędy popełniane w trakcie budowy systemu oceny ofert polegające między innymi na braku zachowania porządku preferencyjnego kwestii/opcji, przeszacowaniu lub niedoszacowaniu wartości kwestii czy opcji w ramach kwestii. Błędy te mogą powstać w wyniku pominięcia przez agentów informacji słownej, a skupienia się tylko na informacji graficznej, lub też w wyniku selektywnego wykorzystania obu typów informacji. Myślenie szybkie (heurystyki) mogło owocować tym, że agenci nie analizowali dokładnie tekstu, a także nie przyglądali się dokładnie rysunkowi. Spostrzerzenia te były podstawą wyodrębnienia trzech rodzajów błędów: porządkowego, skalowania oraz struktury, które poddano dalszej analizie (szerzej punkt 3 pracy, por. [Kersten i in. 2017]). Postawiono następujące pytania badawcze:

Pytanie 1. Jakie sa zależności między błędami porządkowymi, skalowania, struktury popetnionymi przez agenta podczas budowy systemu oceny ofert oraz zakres ich występowania?

Pytanie 2. Czy błędy te maja istotny wplyw na ocenę punktowa porozumienia wedtug systemu oceny ofert agenta?

Pytanie 3. Czy błędy te maja istotny wplyw na ocene punktowa porozumienia wedtug systemu oceny ofert pryncypata?

\section{Negocjacje w Inspire: opis eksperymentu}

System Inspire jest systemem wspomagania negocjacji dwustronnych, działającym w środowisku internetowym. Wykorzystywany w dydaktyce i treningu negocjacyjnym, pozwala na zorganizowanie eksperymentów zarówno studyjnych (tryb negocjacji synchronicznych), jak i zdalnych (tryb negocjacji asynchronicznych). Jako narzędzie treningowo-badawcze umożliwia predefiniowanie problemu negocjacyjnego, ustalenie agendy oraz protokołu negocjacji. Pozwala on również implementować szereg definiowanych przez projektanta eksperymentu ankiet badawczych oraz przeprowadzać predefiniowane testy psychometryczne.

W zorganizowanym na potrzeby niniejszej pracy badaniu w Inspire zaimplementowano problem negocjacyjny, w którym przedstawiciele firmy fonograficznej (Mosico) i piosenkarki (Fado) negocjują kontrakt wydawniczy obejmujący cztery kwestie z następującymi dopuszczalnymi poziomami realizacji (opcjami istotnymi):

- liczba nowych piosenek: od 11 do 15 , 
- $\quad$ tantiemy za CD: 1,$5 ; 2 ; 2,5$ lub 3\%,

- wartość kontaktu: \$125 000; \$150 000; \$200 000,

- liczba koncertów promocyjnych: od 5 do 8 .

Uczestnicy eksperymentu wcielali się w rolę agentów negocjujących w imieniu pryncypała. Struktura preferencji pryncypałów została predefiniowana i przedstawiona agentom w formie graficzno-słownej. Przykład informacji preferencyjnej pryncypała dotyczący istotności opcji kwestii negocjacyjnej „Liczba nowych piosenek" dla agenta Mosico przedstawiono na rys. 1. Analogicznie opisano preferencje dla pozostałych kwestii negocjatora Mosico i Fado.

Liczba nowych piosenek

Ustalono, iż zbyt mało piosenek może mieć katastrofalne

skutki dla promocji artysty, ale zbyt dużo też nie jest korzystne.

Najkorzystniej, gdy artysta skupia się na napisaniu 14 piosenek

rocznie, gdyż 14 piosenek pozwala wydać dwie pełne płyty.

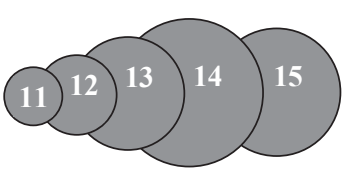

Liczba piosenek

- 15 piosenek to gorzej niż 14 , bo uważa się, iż to zbyt dużo na dwie płyty,

- 13 piosenek to trochę gorzej niż 15,

- 12 piosenek to gorzej niż 13, ponieważ 13 pozostawia nadal możliwość odrzucenia jakieś najgorszej/kontrowersyjnej,

- 11 piosenek to opcja najgorsza, ponieważ pozwala wyprodukować tylko jedną płytę.

Rys. 1. Przykładowa informacja preferencyjna dla Mosico dla kwestii: Liczba nowych piosenek

Źródło: opracowanie własne na podstawie Inspire.

Zgodnie z protokołem negocjacyjnym agenci w fazie prenegocjacyjnej wykorzystywali informację preferencyjna pryncypała do budowy punktowego systemu oceny ofert negocjacyjnych za pomocą metody ratingu bezpośredniego (por. [Kersten $i$ in. 2017]). Rzetelność ich działań można zmierzyć, porównując ich system oceny z systemem referencyjnym, który uzyskać można, na przykład, poprzez dokładny pomiar powierzchni lub promieni kół wizualizujących strukturę kardynalnej zależności preferencji pryncypała, przedstawionej w informacji preferencyjnej. W opracowaniu jako system referencyjny wykorzystano system oparty na pomiarze promieni kół (tab. 1).

Tabela 1. System referencyjny pryncypała

\begin{tabular}{|c|c|c|c|c|c|c|c|c|c|c|c|c|c|c|c|c|}
\hline \multirow{2}{*}{ Pryncypał } & \multicolumn{4}{|c|}{ Koncerty } & \multicolumn{5}{|c|}{ Piosenki } & \multicolumn{4}{|c|}{ Tantiemy } & \multicolumn{3}{|c|}{ Kontrakt } \\
\hline & 5 & 6 & 7 & 8 & 11 & 12 & 13 & 14 & 15 & 1.5 & 2.0 & 2.5 & 3.0 & 125 & 150 & 200 \\
\hline Mosico & 0 & 21 & 26 & 32 & 0 & 7 & 16 & 28 & 21 & 13 & 23 & 16 & 0 & 17 & 10 & 0 \\
\hline Fado & 32 & 25 & 21 & 0 & 0 & 8 & 20 & 32 & 24 & 0 & 7 & 12 & 16 & 0 & 15 & 20 \\
\hline
\end{tabular}

Źródło: opracowanie własne. 
Na podstawie uzyskanych systemów oceny ofert agenci prowadzili negocjacje, które wspierane były przez system Inspire w zakresie oceny ofert przychodzących i wychodzących, wizualizacji historii negocjacji, generowania ofert własnych, prowadzenia komunikacji asynchronicznej i postnegocjacyjej poprawy kompromisu negocjacyjnego (por. [Wachowicz 2006]). W badaniu wykorzystano dane pochodzące z eksperymentu negocjacyjnego Inspire z 2014 roku, w którym rolę agentów pełnili studenci z Austrii, Kanady, Holandii, Polski oraz Tajwanu. Bazę danych tworzyło 286 rekordów opisujących agentów, którzy zakończyli negocjacje porozumieniem.

\section{Metoda badań}

Na potrzeby niniejszego badania wyodrębniono i poddano dalszej analizie następujące rodzaje błędów (por. [Kersten i in. 2017])2:

- Bląd porządkowy (BP) - brak zachowania porządku preferencyjnego wynikającego z informacji preferencyjnej ocen przypisanych do kwestii i opcji negocjacyjnych przez agenta [Roszkowska, Wachowicz 2015].

- Bląd skalowania (BS) - niedoszacowanie lub przeszacowanie wartości opcji/ kwestii przy budowie systemu oceny ofert. Wyróżniono dwie sytuacje:

- BS1: (ocena kwestii) - przypisanie oceny punktowej co najmniej 50 jednej z kwestii negocjacyjnych i co najwyżej 5 drugiej z nich jednocześnie lub przypisanie oceny punktowej 1 co najmniej jednej kwestii negocjacyjnej ${ }^{3}$.

- BS2: (ocena opcji w ramach kwestii) - przypisanie oceny punktowej zero opcji istotnej.

Konsekwencją błędu BS2 jest przypisanie oceny niezerowej opcji nieistotnej (najgorszej) lub też przypisanie oceny zerowej co najmniej dwóm opcjom.

- Błąd struktury (BST) - błąd związany ze specyfiką strukturą preferencji strony negocjacji (np. problem z monotonicznością, jednakowe wagi) (zob. tab. 1) Wyodrębniono następujące błędy specyficzne"

- BSTM: Błąd struktury dla Mosico: $u($ Piosenki13) $\geq u$ (Piosenki15) lub $u$ ( Tantiemy 1,5$) \geq u$ (Tantiemy 2,5$)$

- BSTF: Błąd struktury dla Fado:

$$
\begin{gathered}
\mathrm{u}(\text { Tantiemy }) \geq \mathrm{u}(\text { Kontrakt) lub } \mathrm{u}(\text { Piosenki) } \neq \mathrm{u}(\text { Koncert }) \text { lub } \\
\mathrm{u}(\text { Piosenki13) } \geq \mathrm{u}(\text { Piosenki15) }
\end{gathered}
$$

gdzie: $u(x)$ oznacza ocenę punktową kwestii/opcji $x$.

${ }^{2}$ Należy zaznaczyć, że podana propozycja nie wyczerpuje wszystkich rodzajów błędów, które negocjatorzy mogą popełnić w trakcie budowy systemu oceny ofert, a zaproponowana klasyfikacja jest jedną z możliwych.

${ }^{3}$ Wartości 50 oraz 5 zostały subiektywnie wybrane w celu opisu sytuacji, w której jedna kwestia jest dla negocjatora bardzo ważna, przy znacznej marginalizacji drugiej z nich.

${ }^{4}$ Błędy struktury wyodrębniono, biorąc pod uwagę najczęściej występujące błędy niezgodności porządkowej zaobserwowane przy porównaniu parami kwestii/opcji. 


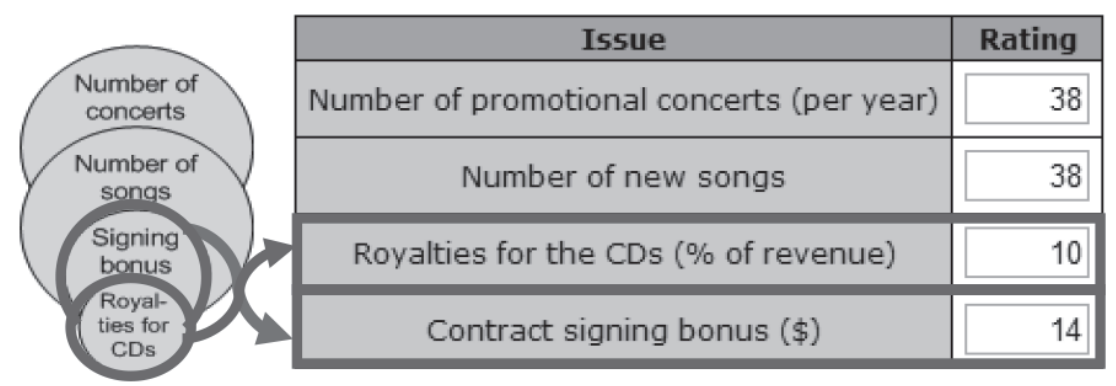

Rys. 2. Graficzna reprezentacja informacji preferencyjnej a interfejs oceny kwestii negocjacyjnych dla Fado

Źródło: System Inspire.

Zauważony dla Fado błąd $\mathrm{u}$ (Tantiemy) $\geq \mathrm{u}$ (Kontrakt) można powiązać $\mathrm{z}$ faktem innej kolejności występowania kwestii negocjacyjnych w prezentacji graficznej informacji preferencyjnej pryncypała w porównaniu kolejnością występowania tych kwestii w interfejsie oceny punktowej zgodnie z procedurą rozdziału 100 punktów w ramach kwestii (rys. 2).

\section{Wyniki}

\subsection{Zależności między błędami oraz zakres ich występowania}

Zależności między błędami BP, BS oraz BST dla agentów Fado (F) oraz Mosico (M) są następujące: $n(\mathrm{BPF})=113, n(B S F)=31, n(\mathrm{BSTF})=104, n(B \mathrm{PF} \cap \mathrm{BSF})=$ $31, n(B S T F \cap \mathrm{BPF})=104, n(B S T F \cap \mathrm{BSF})=28$ dla Fado oraz $n(\mathrm{BPM})=$ $117, n(\mathrm{BSM})=66, n(\mathrm{BSTM})=102, n(\mathrm{BPM} \cap \mathrm{BSM})=65, \quad n(\mathrm{BSTM} \cap \mathrm{BPM})=$ $102, n(B S T M \cap B S M)=53$ dla Mosico. Frakcje błędów porządkowych, skalowania i struktury dla Mosico i Fado przedstawiono na rys. 3.

Najczęściej występujące błędy struktury Mosico związane były z przypisaniem ocen punktowych opcjom o preferencjach niemonotonicznych, a dokładniej z porównaniem opcji skupionych wokół opcji najlepszej (por. tab.1). Na przykład pomimo wyraźnie określonej informacji preferencyjnej zarówno słownej, jak i graficznej (por. rys. 1), iż „13 piosenek to trochę gorzej niż 15”, aż 65 agentów Mosico przyznało więcej punktów 13 piosenkom niż 15 . Błędy struktury dla Fado związane były $\mathrm{z}$ technicznymi zmianami $\mathrm{w}$ sposobie prezentacji informacji preferencyjnej dla kwestii negocjacyjnych (por. rys. 2), problemem przypisania jednakowych wag dla dwóch kwestii (zob. tab. 1) oraz z niemonotonicznością preferencji wobec opcji kwestii Piosenki (tab. 1). Zaobserwowano następujące liczebności błędów struktury dla Mosico: 
- $n(u($ Tantiemy 1.5$) \geq u($ Tantiemy 2.5$))=52$,

- $n(u($ Piosenki 13) $\geq u($ Piosenki 15) $)=86$,

- $n\left(\begin{array}{c}(u(\text { Tantiemy } 1.5) \geq u(\text { Tantiemy } 2.5)) \\ \wedge(u(\text { Piosenki } 13) \geq u(\text { Piosenki } 15))\end{array}\right)=36$.

oraz dla Fado:

- $n(u($ Tantiemy $) \geq u($ Kontrakt $))=58$,

- $n(u$ (Piosenki) $\neq u$ (Koncerty $))=71$,

- $n(u($ Piosenki 13 $) \geq u($ Piosenki 15) $)=49$.

Wyniki badań pokazują na brak zgodności porządkowej dla ponad 79\% Mosico oraz prawie $82 \%$ Fado (rys. 3). Zaobserwowano duże różnice częstości występowania błędów skalowania ze względu na rolę pełnioną przez negocjatorów (rys. 3).

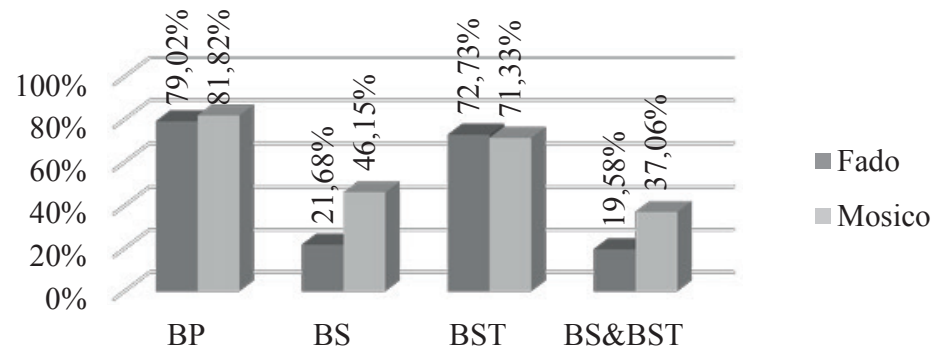

Rys. 3. Frakcje błędów porządkowych, skalowania i struktury dla Mosico i Fado Źródło: opracowanie własne.

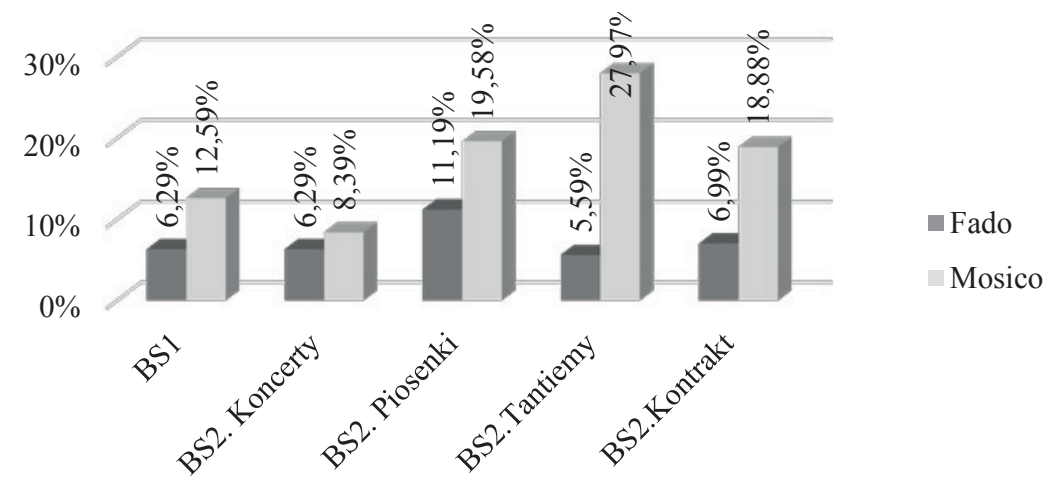

Rys. 4. Frakcje cząstkowych błędów skalowania dla Mosico i Fado Źródło: opracowanie własne. 
Zaobserwowano także różnice częstości występowania błędów skalowania BS1 oraz błędu BS2 z podziałem na kwestie negocjacyjne ze względu rolę pełnioną przez agenta (rys. 4). Poza błędem BS2 dla Koncertów różnice te są statystycznie istotne $(p=0,05)$.

\subsection{Błędy porządkowe, skalowania, struktury a porozumienie końcowe}

W tabeli 2 oraz 3 przedstawiono średnie wyniki porozumienia wg agenta i pryncypała z uwzględnieniem rodzaju błędu. Do porównania zgodności rozkładów porozumienia wg agenta/pryncypała w podziale na klasy ze względu na rodzaj błędu wykorzystano test U Manna-Whitneya. Do porównania zgodności rozkładów porozumienia wg agenta oraz pryncypała w klasie skojarzonej z występowaniem błędu określonego rodzaju wykorzystano test znaków rangowanych Wilcoxona. Test U Manna-Withneya jest alternatywą dla testu t-Studenta dla prób niezależnych, natomiast test Wilcoxona alternatywą dla testu t-Studenta dla prób zależnych o innych rozkładach niż normalne. Wybór obu testów był spowodowany rodzajem prób oraz brakiem spełnienia założeń o normalności rozkładów badanych zmiennych.

Na mocy testu U Manna-Whitney'a stwierdzono istotne różnice w ocenie punktowej porozumienia (tab. 2 i 3 ):

- wg pryncypała Mosico/Fado między agentami, którzy popełniali oraz agentami, którzy nie popełniali błędów skalowania,

- wg pryncypała Mosico między agentami, którzy popełniali oraz agentami, którzy nie popełniali błędów struktury.

Tabela 2. Średnia porozumienia w podziale na klasy ze względu na rodzaj błędu - Fado

\begin{tabular}{|l|c|c|c|}
\hline \multicolumn{1}{|c|}{ Fado } & \multicolumn{2}{|c|}{ Podział na klasy ze względu na rodzaj błędu } & $\begin{array}{c}\text { Test U Manna- } \\
\text {-Whitney'a }(p)\end{array}$ \\
\hline & BP $(\mathrm{N}=113)$ & brak BP $(\mathrm{N}=30)$ & \\
\hline Agent & 80,72 & 84,33 & 0,127 \\
\hline Pryncypał & 76,98 & $\mathbf{8 1 , 0 3}$ & 0,154 \\
\hline Test Wilcoxona $(p)$ & 0,000 & 0,023 & \\
\hline & $\mathrm{BS}(\mathrm{N}=31)$ & brak BS $(\mathrm{N}=112)$ & 0,263 \\
\hline Agent & 76,97 & 82,63 & 0,000 \\
\hline Pryncypał & 68,32 & $\mathbf{8 0 , 4 6}$ & \\
\hline Test Wilcoxona $(p)$ & 0,003 & 0,007 & 0,218 \\
\hline & $\mathrm{BST}(\mathrm{N}=104)$ & brak BST $(\mathrm{N}=39)$ & 0,273 \\
\hline Agent & 80,56 & 83,64 & \\
\hline Pryncypał & 77,05 & $\mathbf{7 9 , 9 2}$ & \\
\hline Test Wilcoxona $(p)$ & 0,001 & 0,003 & \\
\hline
\end{tabular}

Źródło: opracowanie własne. 
Tabela 3. Średnia porozumienia w podziale na klasy ze względu na rodzaj błędu - Mosico

\begin{tabular}{|l|c|c|c|}
\hline \multirow{2}{*}{ Mosico } & \multicolumn{2}{|c|}{$\begin{array}{c}\text { Podział na klasy } \\
\text { ze względu na rodzaj błędu }\end{array}$} & $\begin{array}{c}\text { Test U Manna- } \\
\text {-Whitney'a }(p)\end{array}$ \\
\hline Agent & $\mathrm{BP}(\mathrm{N}=117)$ & brak BP $(\mathrm{N}=26)$ & \\
\hline Pryncypał & 78,05 & 77,54 & 0,990 \\
\hline Test Wilcoxona $(p)$ & 74,80 & 73,65 & 0,663 \\
\hline & 0,003 & 0,009 & \\
\hline Agent & $\mathrm{BS}(\mathrm{N}=66)$ & brak BS $(\mathrm{N}=77)$ & \\
\hline Pryncypał & 76,91 & 78,86 & 0,371 \\
\hline Test Wilcoxona $(p)$ & 72,14 & $\mathbf{7 6 , 7 0}$ & 0,037 \\
\hline & 0,007 & 0,010 & \\
\hline Agent & $\mathrm{BST}(\mathrm{N}=102)$ & brak BST $(\mathrm{N}=41)$ & \\
\hline Pryncypał & 78,26 & 77,20 & 0,738 \\
\hline Test Wilcoxona $(p)$ & 76,03 & 71,02 & 0,011 \\
\hline
\end{tabular}

Źródło: opracowanie własne.

Średnia ocena punktowa porozumienia wg pryncypała w klasie agentów Fado, którzy nie popełniali jednego z trzech analizowanych błędów, była wyższa niż średnia ocena punktowa porozumienia w klasie agentów, którzy ten błąd popełnili. W przypadku Mosico prawidłowość taką zaobserwowano jedynie dla błędów skalowania.

Na mocy testu znakowanych rang Wilcoxona stwierdzono, że mediana różnic między oceną punktową porozumienia agenta a oceną punktową pryncypała jest istotnie różna od zera (tab. 2 i 3):

- w klasie negocjatorów Mosico/Fado, którzy popełniali/nie popełniali błędów porządkowych,

- w klasie negocjatorów Mosico/Fado, którzy popełniali/nie popełniali błędów skalowania,

- w klasie negocjatorów Mosico/Fado, którzy popełniali/nie popełniali błędów struktury.

\section{Wnioski końcowe}

Przedstawione w pracy analizy są kontynuacją badania [Kersten i in. 2017], a uzyskane wyniki z poznawczego punktu widzenia istotnie rozszerzają uzyskane poprzednio wnioski deskryptywne o konkluzje dotyczące wpływów prenegocjacyjnych błędów poznawczych na wyniki uzyskiwane w fazie zamknięcia rozmów. W badaniu eksperymentalnym zaobserwowano duże różnice częstości występowania błędów skalowania ogółem, a także z podziałem na kwestie negocjacyjne ze względu na 
rolę przyjmowaną przez agentów. Najwięcej błędów porządkowych wystąpiło dla niemonotonicznych kwestii negocjacyjnych. Stwierdzono istotne różnice w ocenie punktowej porozumienia wg pryncypała między agentami, którzy popełniali oraz agentami, którzy nie popełniali błędów skalowania niezależnie od roli pełnionej w negocjacjach.

Wyniki badań wskazują więc na potrzebę uwzględnienia heurystyk w procesie prenegocjacyjnego przygotowania analitycznego negocjatorów oraz opracowania narzędzi wsparcia negocjatora odpornych na te heurystyki lub redukujących negatywne ich skutki. Dalsze badania dotyczyć będą identyfikacji czynników behawioralnych, heurystyk związanych z omawianymi błędami i ich wpływu na strukturyzację problemu negocjacyjnego, specyfikację kwestii i ich poziomów realizacji, budowę ofert negocjacyjnych, sposób analizy preferencji oraz wybór metody wielokryterialnej do budowy systemu ocen negocjacyjnych.

\section{Literatura}

Bazerman M.H., Chung D., 2005, Focusing in negotiation, [w:] Thompson L. (red.), Frontiers of Social Psychology: Negotiations, Psychological Press, New York, NY.

Edwards W., Barron F.H., 1994, SMARTS and SMARTER: Improved Simple Methods for Multiattribute Utility Measurement, Organizational Behavior and Human Decision Processes, 60, 306-325.

Gilovich T., Griffin D., Kahneman D., 2002, Heuristics and biases: The psychology of intuitive judgment, Cambridge University Press, Cambridge.

Kersten G.E., Noronha S.J., 1999, WWW-based negotiation support: Design, implementation, and use. Decision Support Systems, 25(2), 135-154.

Kersten G.E., Roszkowska E., Wachowicz T., 2016, An Impact of Negotiation Profiles on the Accuracy of Negotiation Offer Scoring System - Experimental Study, Multiple Criteria Decision Making, 11, 77-103.

Kersten G.E., Roszkowska E., Wachowicz T., 2017, The Heuristics and Biases in Using the Negotiation Support Systems, [w:] Schoop M., Kilgur M. (red.), Group Decision and Negotiation. A Socio-Technical Perspective, Lecture Notes in Business Insformation Processing, 293, Springer, 215-228.

Raiffa H., 1982, The art and science of negotiation, Harvard University Press, Cambridge.

Roszkowska E, Wachowicz T., 2014, SAW-based Rankings vs. Intrinsic Evaluations of the Negotiation Offers - An Experimental Study, [w:] Zaraté P., Kersten G.E. , Hernández J.E. (red.), Group Decision and Negotiation A Process-Oriented View, Springer International Publishing, Heidelberg, s. $176-183$.

Roszkowska E., Wachowicz T., 2015, Inaccuracy in defining preferences by the electronic negotiation system users, Lecture Notes in Business Information Processing, 218, 131-143.

Roszkowska E., Wachowicz T. (red.), 2016, Negocjacje. Analiza i wspomaganeie decyzji, Wolter Kluwer Polska, Warszawa.

Stanovich K.E., West R.F., 2000, Individual Differences in Reasoning: Implications for the Rationality Debate, Behavioral and Brain Sciences, 23, 645-65.

Wachowicz T., 2006, E-negocjacje. Modelowanie, analiza i wspomaganie, Wydawnictwo Akademii Ekonomicznej w Katowicach, Katowice. 